\title{
Malaria case in Madagascar, probable implication of a new vector, Anopheles coustani
}

Thiery N. J. J. Nepomichene ${ }^{1,2^{*}}$, Etienne Tata ${ }^{1}$ and Sébastien Boyer ${ }^{1}$

\begin{abstract}
Background: Indoor spraying of insecticides and the use of insecticide-treated bed nets are key strategies for national malaria vector control in the central highlands of Madagascar. During the year 2013, malaria outbreaks were reported by the National Malaria Control Programme in the highlands, including the district of Ankazobe.

Methods: Entomological trapping was carried out in April and May 2013 and in March 2014, using human landing catches, collection of mosquitoes resting in stables and in houses by oral aspirators, and Centers for Disease Control and Prevention light traps. Detection of Plasmodium in mosquitoes was carried out on head and thorax of anopheline females by ELISA, CSP and PCR (Plasmodium falciparum, Plasmodium malariae, Plasmodium vivax, or Plasmodium ovale). Human biting rate (HBR), sporozoite index and entomological infection rate (EIR) were calculated for Anopheles funestus, Anopheles arabiensis, Anopheles mascarensis, and Anopheles coustani.

Results: In Ankazobe district, the presence of malaria vectors such as An. funestus, An. arabiensis and An. mascarensis was confirmed, and a new and abundant potential vector, An. coustani was detected. Indeed, one individual of An. funestus and two An. coustani were detected positive with P. falciparum while one An. mascarensis and four An. coustani were positive with P. vivax. For An. coustani, in March 2014, the ElR varied from 0.01 infectious bites/person/ month (ipm) outdoors to $0.11 \mathrm{ipm}$ indoors. For An. funestus, in April 2013, the EIR was $0.13 \mathrm{ipm}$. The highest HBR value was observed for An. coustani, 86.13 ipm outdoors. The highest sporozoite rate was also for An. coustani, $9.5 \%$ of An. coustani caught in stable was sporozoite positive.
\end{abstract}

Conclusion: The implication of An. coustani in malaria transmission was not previously mentioned in Madagascar. Its very high abundance and the detection of Plasmodium coupled with an opportunistic feeding behaviour in villages with malaria cases supports its role in malaria transmission in Madagascar.

Keywords: Malaria, Plasmodium falciparum, Plasmodium vivax, Anopheles arabiensis, Anopheles funestus, Anopheles mascarensis, Anopheles coustani, Madagascar

\section{Background}

In Central Highlands of Madagascar (CHM), an intensive campaign to eliminate malaria begun in 1949 by applying indoor residual spraying (IRS) with DDT [1]. The abandonment of IRS in 1979, the discontent with health structures with a slow erosion of health facilities combined with the absence of drug stock and medical staff absenteeism led to a malaria outbreak in 1986 [2-5]. In response, a vector control program was implemented

\footnotetext{
*Correspondence: Jthiery@pasteur.mg

1 Unité d'Entomologie Médicale, Institut Pasteur de Madagascar, BP 1274,

Ambatofotsikely, 101 Antananarivo, Madagascar

Full list of author information is available at the end of the article
}

with DDT in CHM from 1993 to 1998. From 1999, systematic IRS was replaced by selective operations in restricted areas $900 \mathrm{~m}$ above sea level (asl) in CHM. In 2005, carbamate insecticide replaced DDT.

Anopheles funestus, Anopheles mascarensis, Anopheles gambiae s.s., Anopheles arabiensis, and Anopheles merus were considered primary vectors of malaria in Madagascar [6-9]. Anopheles funestus was considered the major vector of Plasmodium falciparum malaria in the CHM and $A n$. arabiensis a secondary vector. Following the residual spraying from 1949 to 1979 , An. funestus disappeared from most CHM villages [3, 5, 10]. Its re-invasion was mentioned in CHM in 1986 [2-5]; malaria outbreaks 
occurred with one specimen of An. funestus detected positive with Plasmodium despite a low abundance [5]. Other species such as An. coustani, Anopheles squamosus/cydippis were suspected to contribute to the epidemic [5]. However, to date, there have been no specific studies carried out on An. coustani and An. squamosus/ cydippis.

Twenty-seven years after the last epidemic, a malaria outbreak resurged in the CHM in 2013. A high number of malaria cases were declared in Ankazobe district. The present work had the objective to identify the malaria vectors in CHM that could be responsible for the epidemic.

\section{Methods}

\section{Study sites and period of capture}

Entomological surveys were conducted in two communes: Kiangara and Marondry within the Ankazobe district (Fig. 1). The site of Andranovelona II (Site I, S $18^{\circ} 23^{\prime} 25.2^{\prime \prime} / \mathrm{EO} 47^{\circ} 01^{\prime} 00.0^{\prime \prime}$ ) was sampled in April and May 2013 whereas the sites of Bemasoandro (Site A, $17^{\circ} \mathrm{S}$ $57^{\prime} 26 ; 47^{\circ} \mathrm{EO} 02^{\prime} 60$ ), Kianjasoa (Site B, $17^{\circ} \mathrm{S} 58^{\prime} 25 ; 47^{\circ} \mathrm{EO}$ $01^{\prime} 80$ ), Ambohimiadana (Site C, $17^{\circ} \mathrm{S} 58^{\prime} 59 ; 47^{\circ}$ EO $03^{\prime} 26$ ), Ambohimanjaka (Site D, $17^{\circ} \mathrm{S} 59^{\prime} 27 ; 47^{\circ} \mathrm{EO} 02^{\prime} 07$ ),
Morafeno (Site E, $18^{\circ} \mathrm{S} 24^{\prime} 13 ; 47^{\circ} \mathrm{EO} 03^{\prime} 03$ ), Miarinarivo Sud (Site F, $18^{\circ} \mathrm{S} 26^{\prime} 05 ; 47^{\circ} \mathrm{EO} 00^{\prime} 02$ ), Voninahitrinitany (Site G, $18^{\circ} \mathrm{S} 31^{\prime} 50 ; 47^{\circ} \mathrm{EO} 01^{\prime} 42$ ), and Tsarahonenana (Site H, $18^{\circ} \mathrm{S} 33^{\prime} 30 ; 47^{\circ} \mathrm{EO} 01^{\prime} 49$ ) were sampled in March 2014 (Fig. 1). In April 2013, human landing catches (HLC), Centers for Disease Control and Prevention simple light traps (CDC LT), collection of mosquitoes resting indoors (MRI) and collection of mosquito resting in stables by oral aspirator were carried out. In May 2013 and March 2014, collection of mosquitoes resting in stables and HLC were carried out, respectively.

\section{Human landing catches}

HLC were performed over two consecutive nights from the local population from 18:00 to 08:00 $\mathrm{h}$ in four different houses with two adult volunteers per house: one located inside and another one outside [11]. Mosquitoes coming to bite the collectors were detected using a flashlight, collected with glass tubes and placed in the collecting bags every hour. The four houses were chosen randomly in the village with no repetition. The capturers took one tablet of doxycycline over 5 days as prophylaxis against infection with the malaria parasite. The HLC were approved by the local health authority.

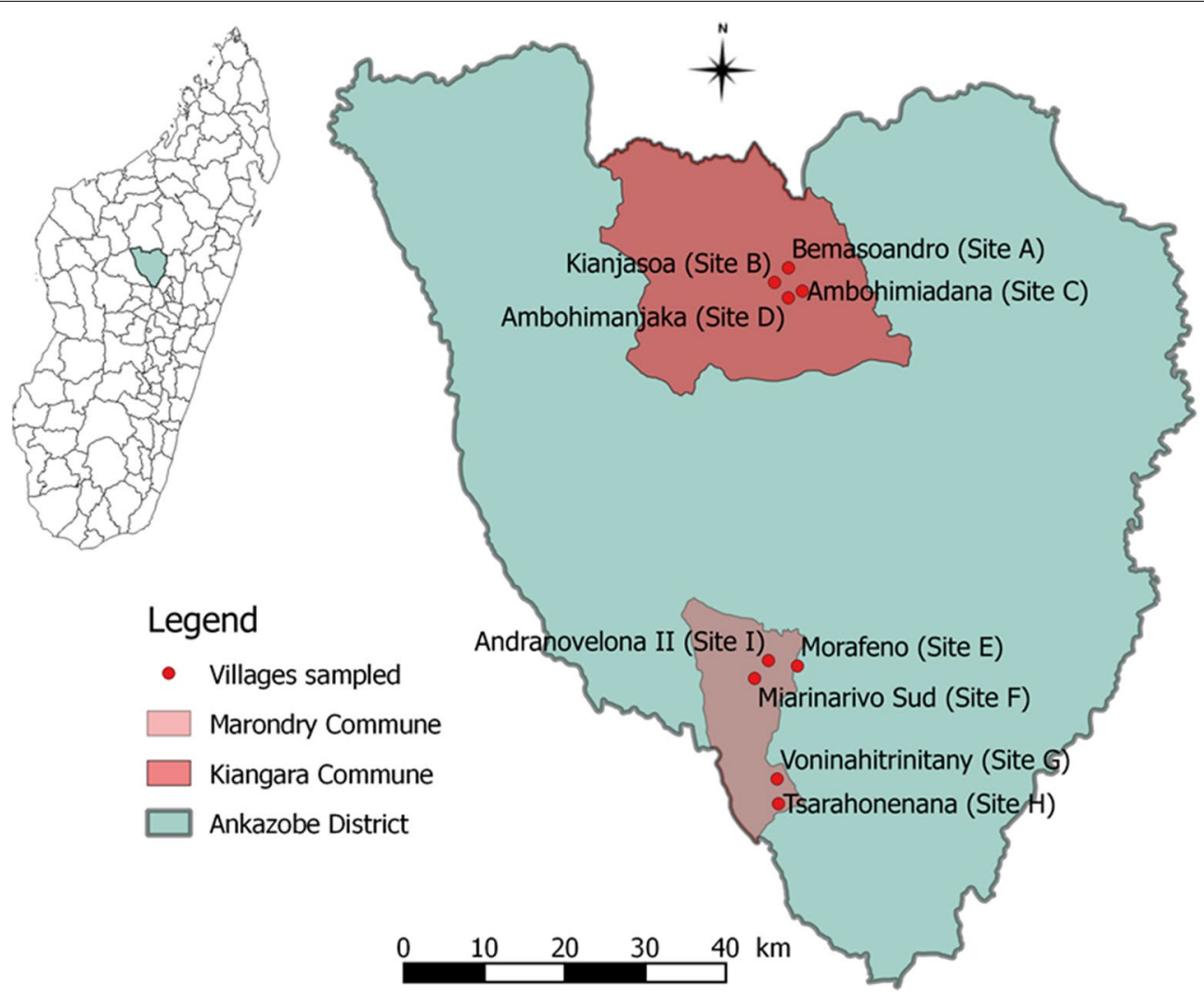

Fig. 1 Study sites 


\section{Centers for Disease Control and Prevention simple light traps}

CDC LT is a system that incorporates a mini-light source attracting mosquitoes, which are drawn in through the top of the trap and forced downwards by the fan into the collection bag-net. Light traps were powered by $6 \mathrm{~V}$ batteries. Six CDC LT were set before sunset (18:00 h) and off after sunrise $(06: 00 \mathrm{~h})$. The CDC LT was set up outdoors over two successive nights.

\section{Collection of mosquitoes resting indoors}

A spraying of non-remanent insecticide was performed in five houses chosen randomly where no HLC and CDC LT were made. Doors and windows were closed and eaves, which allow mosquitoes to escape from houses, were covered during the spraying. After $15 \mathrm{~min}$, all dead and paralyzed mosquitoes fell onto sheets placed on the floor and over the beds and furniture before the spraying. All mosquitoes were collected and identified. Those identified as anophelines were preserved for further analysis. MRI was carried out between 06:00 and 08:00 h over 2 days.

\section{Collection of mosquito resting in stables}

On the first and second day, two entomologists went into stables and caught mosquitoes with oral aspirators. Two stables were sampled during two mornings between 07:00 and 09:00 h.

\section{Identification}

Mosquito identification was performed with the aid of a binocular microscope following the morphological keys [12] and (Fontenille, personal communication). Identifications were carried out in the field. Legs or wings of mosquitoes from the An. gambiae complex were used for PCR identification [13]. The amplification was done under the following conditions: $5 \mathrm{~min}$ at $94{ }^{\circ} \mathrm{C}$ followed by 30 cycles of $1 \mathrm{~min}$ at $94{ }^{\circ} \mathrm{C}, 50 \mathrm{~s}$ at $50{ }^{\circ} \mathrm{C}$ and $50 \mathrm{~s}$ at $72{ }^{\circ} \mathrm{C}$, with a final elongation step $\left(5 \mathrm{~min}\right.$ at $\left.72{ }^{\circ} \mathrm{C}\right)$. The sizes of the fragments obtained were, respectively, 315, 390 and 464 base pairs for An. arabiensis, An. gambiae s.s. and An. merus.

\section{Estimation of the entomological indices}

Detection of Plasmodium in mosquitoes was carried out with head and thorax of all female anopheline species by ELISA CSP screening. Any sample positive following ELISA CSP screening were tested in monospecific ELISA CSP (for identification of P. falciparum, Plasmodium vivax) [14] and in PCR (for identification of $P$. falciparum, Plasmodium malariae, P. vivax, or Plasmodium ovale) [15]. To avoid false positive, lysates were not heated as previously described $[16,17]$ but all specimens were confirmed in PCR. To avoid contamination during the grinding, each specimen was put in a 1.5-ml Epperdorff with $3 \mathrm{ml}$ of steel beads. Then, they were ground in Tissulyser (Tissulyser II, Qiagen ${ }^{\circledR}$ ).

Human biting rate (HBR) was estimated for An. funestus, An. mascarensis, An. arabiensis, and An. coustani. For the sample positive to Plasmodium, the entomological infection rate (EIR) and the sporozoite indices were estimated. HBR is the number of bite for a given vector per person per night (bpn). The EIR is the product of the HBR, the number of bites per person per month by vector mosquitoes and the fraction of vector mosquitoes that are infectious (the sporozoite rate). The sporozoite index indicates the proportion of individual positive with Plasmodium among the total individuals caught for one species. These indices were calculated based on the HLC in April 2013 and March 2014.

\section{Blood meal analyses}

Blood meal analyses were performed on blood fed females caught in stables in May 2013. Direct ELISA as previously described using antihost (IgG) conjugate against human, cow, chicken, and pig proteins were carried out [18].

\section{Results \\ Trapping}

A total of 8549 mosquitoes representing five genera and 23 species were caught (Table 1). The most abundant mosquito species were An. coustani ( $\mathrm{n}=3867$; $45.22 \%$ ), An. squamosus/cydippis ( $\mathrm{n}=1284 ; 15.02 \%)$, An. mascarensis ( $\mathrm{n}=1240 ; 14.50 \%)$, An. funestus ( $\mathrm{n}=542 ; 6.34 \%)$, and $A n$. arabiensis $(\mathrm{n}=408,4.77 \%)$ (Table 1$)$.

In April 2013, 2413 mosquitoes belonging to 15 species were caught during the two consecutive nights with eight Anopheles, six Culex and one Mansonia species. The most abundant species was An. coustani ( $\mathrm{n}=1578$; $69.79 \%$ ) (Table 1). Comparing the trophic behaviour, An. funestus and An. mascarensis had endophagous behaviour while An. coustani and An. arabiensis were endo-exophagous (Fig. 2). One An. arabiensis, three $A n$. funestus and one An. coustani were caught with MRI. Overall, vectors were more abundant in stables compared to indoors (Table 1).

Following the results in April 2013, the stables were specifically targeted for sampling in May 2013. During 2 days, nine species were caught, representing a total of 958 mosquitoes including 869 primary malaria vectors: An. mascarensis ( $\mathrm{n}=531,55.54 \%)$, An. funestus ( $\mathrm{n}=239,25.00 \%$ ) and An. arabiensis ( $\mathrm{n}=99,10.36 \%)$; 21 An. coustani and 49 An. squamosus/cydippis specimens were caught in stables (Table 1). Comparing the three An. funestus caught with MRI during the first 
Table 1 Total number and relative abundance of each species captured during the study

\begin{tabular}{|c|c|c|c|c|c|c|c|c|}
\hline \multirow[t]{2}{*}{ Species } & \multicolumn{4}{|c|}{ Marondry April 2013} & \multirow{2}{*}{$\begin{array}{l}\text { Marondry May } 2013 \\
\text { Stables }\end{array}$} & \multirow{2}{*}{$\begin{array}{l}\text { Marondry March } \\
2014 \\
\text { HLC }\end{array}$} & \multirow{2}{*}{$\begin{array}{l}\text { Kiangara March } \\
2014 \\
\text { HLC }\end{array}$} & \multirow[t]{2}{*}{ Total number (RA \%) } \\
\hline & Stable & $\mathrm{HLC}$ & MRI & CDC LT & & & & \\
\hline An. coustani & 9 & 835 & 1 & 732 & 21 & 1856 & 412 & $3866(45.22)$ \\
\hline $\begin{array}{l}\text { An. squamosus/cydip- } \\
\text { pis }\end{array}$ & 8 & 102 & 0 & 195 & 49 & 520 & 410 & $1284(15.02)$ \\
\hline An. mascarensis & 14 & 28 & 0 & 105 & 531 & 251 & 311 & $1240(14.50)$ \\
\hline An. funestus & 34 & 41 & 3 & 10 & 239 & 195 & 20 & $542(6.34)$ \\
\hline An. arabiensis & 83 & 39 & 1 & 4 & 99 & 37 & 145 & $408(4.77)$ \\
\hline Cx. quinquefasciatus & 0 & 0 & 0 & 3 & 0 & 49 & 308 & $360(4.21)$ \\
\hline Cx.antennatus & 0 & 12 & 0 & 35 & 13 & 115 & 100 & $275(3.22)$ \\
\hline Ma. uniformis & 0 & 2 & 0 & 0 & 1 & 42 & 73 & $118(1.38)$ \\
\hline An.rufipes & 0 & 2 & 0 & 61 & 3 & 3 & 43 & $112(1.31)$ \\
\hline Cx. giganteus & 0 & 3 & 0 & 4 & 0 & 51 & 54 & $112(1.31)$ \\
\hline An.pretoriensis & 0 & 0 & 0 & 0 & 0 & 0 & 71 & $71(0.83)$ \\
\hline An. maculipalpis & 0 & 3 & 0 & 27 & 2 & 0 & 19 & $51(0.60)$ \\
\hline Cx.poïcilipes & 0 & 0 & 0 & 0 & 0 & 30 & 0 & $30(0.35)$ \\
\hline Cx. univittatus & 0 & 0 & 0 & 8 & 0 & 15 & 7 & $30(0.35)$ \\
\hline Ae. tiptoni & 0 & 0 & 0 & 0 & 0 & 4 & 11 & $15(0.18)$ \\
\hline Cx. decens & 0 & 0 & 0 & 0 & 0 & 4 & 6 & $14(0.16)$ \\
\hline Other species & 0 & 2 & 0 & 5 & 0 & 7 & 11 & $23(0.27)$ \\
\hline Total number & 148 & 1069 & 5 & 1189 & 958 & 3179 & 2001 & 8549 \\
\hline
\end{tabular}

Stables collection of mosquitoes in stables by oral aspirator, $M R I$ collection of mosquitoes resting indoors after spraying of non-remanent insecticide, $C D C L T C$ enters for Disease Control and Prevention simple light trap placed indoors and outdoors, HLC human landing catch indoors and outdoors, RA relative abundance. An., $C X ., A e$., Ma. respectively for Anopheles, Culex, Aedes, Mansonia. Other species include An. flavicosta, Cx. bitaeniorhynchus, Ae. albopictus, Ae. argenteopunctatus, Ae. fowleri and Coquellittidia grandidieri. Italics face indicates that malaria vectors are among the abundant species

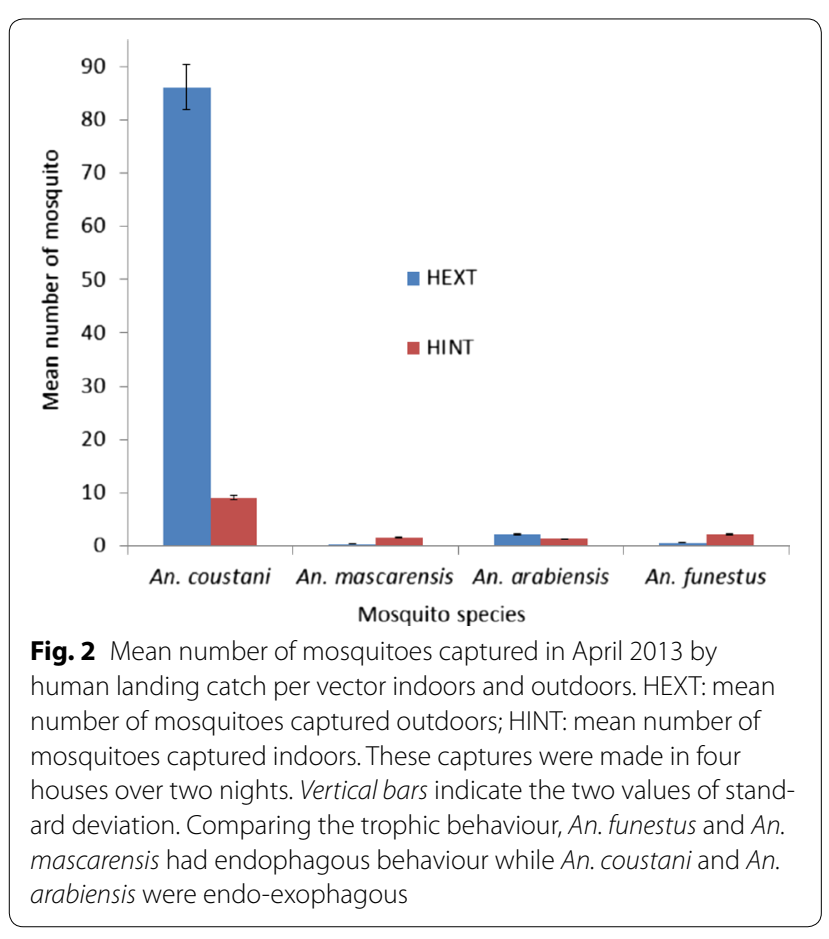

mission, the question arises regarding the endophily of this species.

In March 2014, 5180 mosquitoes belonging to 22 species were caught over the two consecutive nights with nine Anopheles, seven Culex, four Aedes, one Mansonia, and one Coquillettidia species. The most abundant species was An. coustani ( $\mathrm{n}=2268,43.78 \%$ ) (Table 1$)$. For An. coustani, the aggressive biting activity began earlier, i.e., before 18:00 h; $38.05 \%$ of An. coustani bit humans between 18:00 and 21:00 $\mathrm{h}$ and from 05:00 to 08:00 h. In term of human frequency contact, humans are exposed to An. coustani because they are not under treated mosquito nets during these times. Anopheles mascarensis, An. arabiensis and An. funestus had the standard aggressiveness over the night (Fig. 3). Comparing the trophic behaviour, An. coustani, An. arabiensis and An. mascarensis had exophagous behaviour while An. funestus was endophagous from 18:00 to 22:00 $\mathrm{h}$ and exophagous from 23:00 to 07:00 $\mathrm{h}$ (Fig. 3).

\section{Entomological indices}

In April 2013, one sample among the 253 primary vectors, An. funestus, was confirmed to be infected with $P$. 

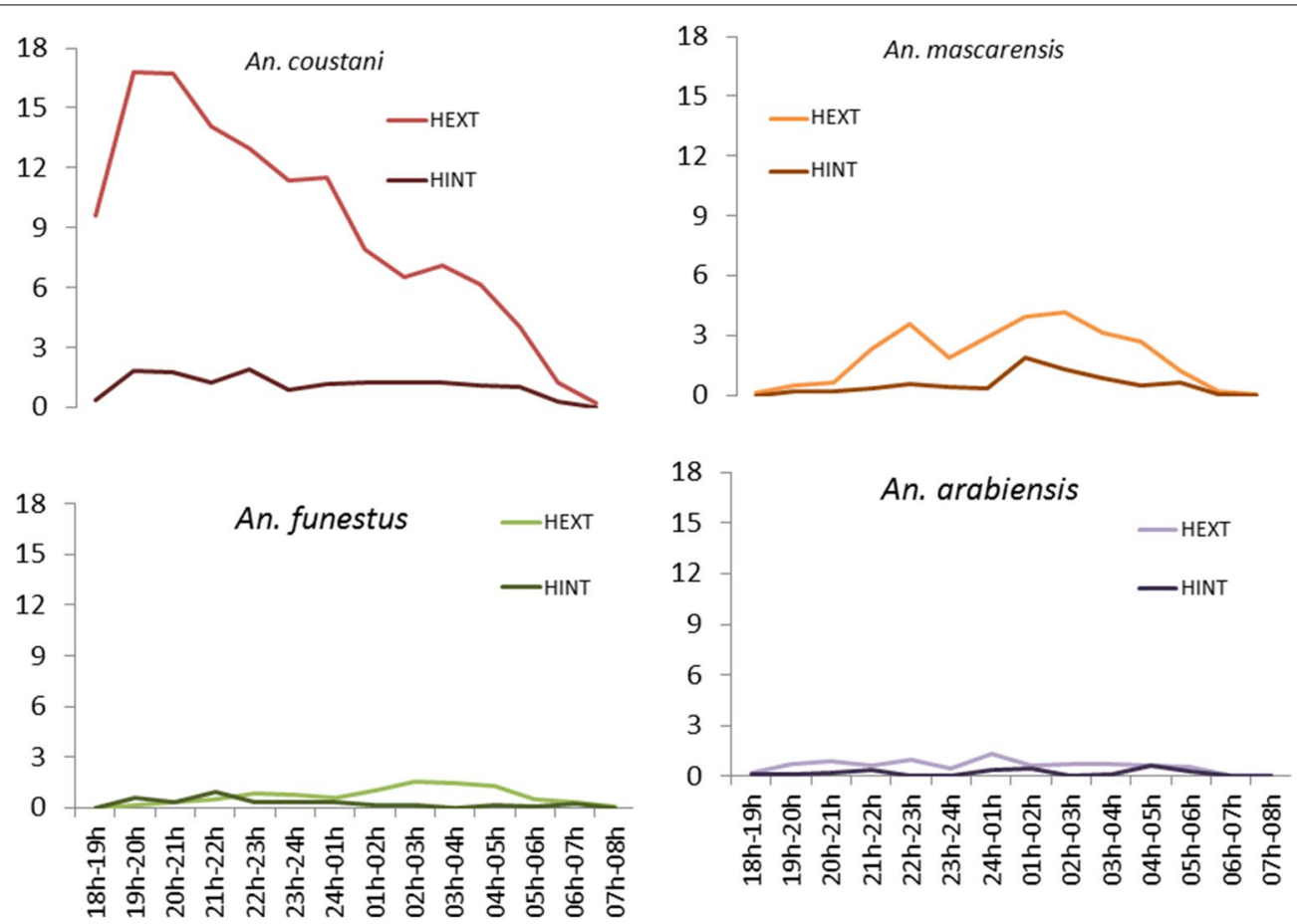

Fig. 3 Mean number of mosquitoes captured in March 2014 by human landing catch per species indoors and outdoors. HEXT: mean number of mosquitoes captured outdoors; HINT: mean number of mosquitoes captured indoors. These captures were made in four houses over two nights in eight villages. For An. coustani, 38.05 \% bite on humans from 18:00 to 21:00 and 05:00 to 08:00 h. Humans are not under treated mosquito nets during these times. Anopheles mascarensis, An. arabiensis and An. funestus had the standard aggressiveness over the night. Comparing the trophic behaviour, An. coustani, An. arabiensis and An. mascarensis had exophagous behaviour while An. funestus had endophagous from 18:00 to 22:00 $\mathrm{h}$ and exophagous from 23:00 to 07:00 $\mathrm{h}$

falciparum. This specimen was captured indoors (Site I): the EIR was 0.21 infectious bite/person/month (ipm) (Table 2). The sporozoite index indoors for this species was 0.03 (i.e., $3 \%$ of An. funestus caught were sporozoite positive).

In May 2013, two An. coustani (representing a sporozoite index of $9.5 \%$ of all caught An. coustani) were confirmed to be infected with $P$. vivax. Among the 869 primary vectors, one An. mascarensis ( $0.18 \%$ of An. mascarensis) was positive with $P$. vivax.

In March 2014, no primary vector was positive but four An. coustani were positive with Plasmodium. Two were positive with $P$. vivax and two with P. falciparum. These specimens were captured indoors (Site A) and outdoors (Sites F, H). The EIR was $0.11 \mathrm{ipm}$ indoors (Site A) and $0.01 \mathrm{ipm}$ outdoors (for each Sites F, H) (Table 2).

The HBR values of each site for each vector were presented in Table 2. It was higher outdoors than indoors and varied from site to site. For An. coustani, the value of HBR can reach up to $86.13 \mathrm{bpn}$ outdoors and $18.25 \mathrm{bpn}$ indoors (Site I). For the primary vector, it varied from 0 bpn indoors to $9.00 \mathrm{bpn}$ outdoors for An. mascarensis, from 0 to $4.9 \mathrm{bpn}$ for An. arabiensis and 0-4.50 bpn for An. funestus.

\section{Blood meal analyses}

In stables, all caught mosquitoes were blood fed females ( $\mathrm{n}=958 / 958$ ). The anthropophily rate was only $7.90 \%$ $(\mathrm{n}=39 / 494)$. This anthropophilic rate was $0.96 \%$ $(\mathrm{n}=2 / 21)$ for $A n$. coustani. Among the main vectors, $A n$. funestus regarded as an anthropophilic vector, had only $8.30 \%$ of human blood, $7.90 \%$ for An. mascarensis and $6.90 \%$ for An. arabiensis. The other blood meal source detected was from cow blood. No blood meals from pig or from chicken were identified.

\section{Discussion}

Six An. coustani females were found positive with P. vivax and $P$. falciparum in the field. This isolation of pathogens from wild-caught mosquitoes is one criterion to state a given species as a potential vector [19]. With the high density of An. coustani during entomological investigations, this species could play a role in the maintenance of Plasmodium transmission during the rainy season, even during the dry season. The public health importance of An. coustani has not previously been described. In 1988, An. coustani and An. squamosus/cydippis were suspected to transmit malaria in $\mathrm{CHM}$ due to their abundance 
Table 2 Human biting rate (HBR), sporozoite indices (SI) and entomological infection rate (EIR) for each vector in each site

\begin{tabular}{|c|c|c|c|c|c|c|c|c|c|}
\hline \multirow[t]{2}{*}{ Sites } & \multirow[t]{2}{*}{ Entomological indices } & \multicolumn{2}{|c|}{ An. arabiensis } & \multicolumn{2}{|c|}{ An. coustani } & \multicolumn{2}{|c|}{ An. funestus } & \multicolumn{2}{|c|}{ An. mascarensis } \\
\hline & & HEXT & HINT & HEXT & HINT & HEXT & HINT & HEXT & HINT \\
\hline \multirow[t]{4}{*}{ Site A } & No & 45 & 23 & 133 & 28 & 0 & 2 & 90 & 62 \\
\hline & $\mathrm{HBR}$ & 4.50 & 2.30 & 13.30 & 2.80 & 0 & 0.20 & 9.00 & 6.20 \\
\hline & $\mathrm{SI}$ & - & - & - & 0.04 & - & - & - & - \\
\hline & $E I R$ & - & - & - & 0.11 & - & - & - & - \\
\hline \multirow[t]{2}{*}{ Site B } & No & 10 & 4 & 51 & 15 & 3 & 3 & 43 & 19 \\
\hline & $\mathrm{HBR}$ & 1.00 & 0.40 & 5.10 & 1.50 & 0.30 & 0.30 & 4.30 & 1.90 \\
\hline \multirow[t]{2}{*}{ Site C } & No & 49 & 10 & 84 & 39 & 5 & 2 & 70 & 14 \\
\hline & $\mathrm{HBR}$ & 4.90 & 1.00 & 8.40 & 3.90 & 0.50 & 0.20 & 7.00 & 1.40 \\
\hline \multirow[t]{2}{*}{ Site D } & No & 2 & 2 & 57 & 5 & 4 & 1 & 12 & 1 \\
\hline & $\mathrm{HBR}$ & 0.20 & 0.20 & 5.70 & 0.50 & 0.40 & 0.10 & 1.20 & 0.10 \\
\hline \multirow[t]{2}{*}{ Site $\mathrm{E}$} & No & 1 & 2 & 363 & 34 & 98 & 36 & 71 & 13 \\
\hline & $\mathrm{HBR}$ & 0.10 & 0.20 & 36.30 & 3.40 & 9.80 & 3.60 & 7.10 & 1.30 \\
\hline \multirow[t]{4}{*}{ Site F } & No & 26 & 3 & 461 & 10 & 27 & 1 & 33 & 0 \\
\hline & $\mathrm{HBR}$ & 2.60 & 0.30 & 46.10 & 1.00 & 2.70 & 0.10 & 3.30 & 0 \\
\hline & $\mathrm{SI}$ & - & - & 0.01 & - & - & - & - & - \\
\hline & $E I R$ & - & - & 0.01 & - & - & - & - & - \\
\hline \multirow[t]{2}{*}{ Site G } & No & 4 & 1 & 505 & 95 & 9 & 14 & 37 & 4 \\
\hline & $\mathrm{HBR}$ & 0.40 & 0.10 & 50.50 & 9.50 & 0.90 & 1.40 & 3.70 & 0.40 \\
\hline \multirow[t]{4}{*}{ Site $\mathrm{H}$} & No & 0 & 0 & 368 & 20 & 8 & 2 & 85 & 8 \\
\hline & HBR & 0 & 0 & 36.80 & 2.00 & 0.80 & 0.20 & 8.50 & 0.80 \\
\hline & $\mathrm{SI}$ & - & - & 0.01 & 0.05 & - & - & - & - \\
\hline & $E I R$ & - & - & 0,01 & - & - & - & - & - \\
\hline \multirow[t]{4}{*}{ Site I } & No & 18 & 21 & 689 & 146 & 5 & 36 & 3 & 25 \\
\hline & $\mathrm{HBR}$ & 2.25 & 2.63 & 86.13 & 18.25 & 0.63 & 4.50 & 0.38 & 3.13 \\
\hline & SI & - & - & - & - & - & 0.03 & - & - \\
\hline & $E I R$ & - & - & - & - & - & 0.21 & - & - \\
\hline
\end{tabular}

HBR human biting rate, the number of bite per person per night; SI sporozoite indices, the proportion of individual positive with Plasmodium among the total individuals caught for one species, EIR entomological infection rate: the number of infecting bite per person per site per month. In April 2013 , one sample among the 253 primary vectors, An. funestus, was confirmed to be infected with P. falciparum. This specimen was captured indoors (Site I). In March 2014 , no primary vector was positive but four An. coustani were positive: two were positive with P. vivax and two with $P$. falciparum. These specimens were captured indoors (Site A) and outdoors (Sites F, H). Italics face indicates that HBR is very high for An. coustani mainly outdoors

[5]. Anopheles coustani was reported in high numbers in all regions of Madagascar up to $1900 \mathrm{~m}$ asl [12, 20]. The involvement of $A n$. coustani in malaria transmission was also suspected in other countries. In Zambia, these mosquitoes were suspected of being a potential secondary vector according to the large proportion of caught mosquitoes anophelines coupled with an anthropophilic behaviour [21].

Ankazobe is definitively an area favourable to Anopheles species in the CHM. Importantly, the three main vectors were present together with significant densities at the end of the rainy season in stables, which are noninsecticide-treated areas. The number of vectors, including $A n$. coustani, was very important during this study despite the low sampling effort. Even considering a low anthropophilic index for $A n$. coustani, this potential vector was detected with human blood, reflecting human/ vector contact. Moreover, the high level of HBR mainly outdoors for An. coustani, compared to the primary vector, supports contact of this vector with humans. In addition, CDC LT captured this species, suggesting that the CDC LT could be an alternative for HLC.

Vector control using IRS and insecticide-treated bed nets is the key strategy to protect humans from mosquito bites in Madagascar. In response, changes in trophic behaviour of vector species was reported [22, 23]. The bite could have occurred in the evenings or mornings when people are active outdoors and unprotected [24]. To evade insecticide, vectors could also change their feeding times, their home visit time and resting places 
[25]. The definition of endophilic and exophilic became ambiguous because if these terms were related to humans, mosquitoes captured in stables were exophilic. If not, all mosquitoes captured in stables were endophilic and zooendophagic. In Madagascar, stables are not insecticidetreated and are often attached to houses. Mosquitoes can bite in houses and exit rapidly for resting in stables. This phenomenon reduces contact with insecticide and its impact [25]. This trophic behaviour change requires a new strategy in vector control because stables must be treated. A slight change of An. funestus behaviour was detected ten years ago in Madagascar with the hypothesis of a change from human to animal biting [26]. This feeding preference change was observed during this study with less than $10 \%$ of human blood-engorged females.

\section{Conclusion}

During this study, An. coustani species were positive with $P$. falciparum and $P$. vivax. The very high abundance and detection of Plasmodium coupled with opportunistic feeding behaviour in villages with malaria cases supports its role in malaria transmission in Madagascar. Regarding insecticide treatment against the vectors, not only houses but also stables, as major resting sites of Anopheles vector species, need to be treated as priority. The current and rapid changes of behaviour of the main vectors and the implication of $A n$. coustani as a new vector require an adaptation of control methods.

\section{Abbreviations}

Asl: above sea level; bpn: bite/person/night; CDC: Centers for Disease Control and Prevention; CHM: Central Highlands of Madagascar; CSP: circumsporozoite protein; DDT: dichlorodiphenyltrichloroethane; EIR: entomological infection rate; ELISA: enzyme-linked immunosorbent assay; HBR: human biting rate; HLC: human landing catch; ipm: infectious bite/person/month; IRS: indoor residual spraying; LLIN: long-lasting insecticidal nets; LT: light trap; MRI: mosquitoes resting indoors; PCR: polymerase chain reaction; SI: sporozoite indices.
\end{abstract}

\section{Authors' contributions}

SB and TNJJN participated in the study design, data collection, data analysis and drafted the manuscript. SB, TNJJN and ET participated in data collection, carried out the ELISA CSP and PCR identification of Anopheles gambiae complex. All authors read and approved the final manuscript.

\section{Author details}

${ }^{1}$ Unité d'Entomologie Médicale, Institut Pasteur de Madagascar, BP 1274, Ambatofotsikely, 101 Antananarivo, Madagascar. ${ }^{2}$ Ecole doctorale Sciences de la vie et de l'environnement, Université d'Antananarivo, Antananarivo, Madagascar.

\section{Acknowledgements}

This research was supported by the Institut Pasteur de Madagascar. We are thankful to Christophe Rogier for the funding of this entomological monitoring. We are grateful to the entomological technicians Lala Andrianaivolambo, Jean Claude Rakotoniaina and Maminirina Fidelis Ambinintsoa. We want to acknowledge the important work of the local population during the capture of mosquitoes.

\section{Competing interests}

The authors declare that they have no competing interests.
Received: 28 July 2015 Accepted: 19 November 2015

Published online: 01 December 2015

\section{References}

1. Randriantsimaniry D. Lutte antivectorielle dans l'épidémie des plateaux de Madagascar. Cahiers d'études et de recherches francophones/Santé. 1995;5:392-6.

2. Mouchet J, Carnevale P, Coosemans M, Julvez J, Manguin S, RichardLenoble D, et al. Biodiversité du paludisme dans le monde. Montrouge: John Libbey Eurotext; 2004.

3. Lepers JP, Fontenille D, Rason MD, Chougnet C, Astagneau P, Coulanges $\mathrm{P}$, et al. Transmission and epidemiology of newly transmitted falciparum malaria in the central highland plateaux of Madagascar. Ann Trop Med Parasitol. 1991;85:297-304.

4. Rakotomanana F, Jeanne I, Duchemin JB, Pietra V, Raharimalala L, Tombo $\mathrm{ML}$, Ariey F. Geographic approach in malaria control in the central highlands of Madagascar (in French). Arch Inst Pasteur Madag. 2000;67:27-30.

5. Fontenille D, Rakotoarivony I. Reappearance of Anopheles funestus as a malaria vector in the Antananarivo region, Madagascar. Trans R Soc Trop Med Hyg. 1988:82:644-5.

6. Leong PockTsy J-M, Duchemin J-B, Marrama L, Rabarison P, Le Goff G, Rajaonarivelo V, et al. Distribution of the species of the Anopheles gambiae complex and first evidence of Anopheles merus as a malaria vector in Madagascar. Malar J. 2003;2:33.

7. Chauvet G, Coz J, Gruchet H, Grjébine A, Lumaret R. Contribution à l'étude biologique des vecteurs du paludisme à Madagascar: résultats de 5 années d'études (1958-1962). Med Trop (Mars). 1964;24:27-44.

8. Le Goff G, Léong Pock Tsy JM, Robert V. Molecular characterization of the malaria vector Anopheles gambiae s.s. in Madagascar. Med Vet Entomol. 2006;20:259-60.

9. Marrama L, Jambou R, Rakotoarivony I, Léong Pock Tsy JM, Duchemin $J B$, Laventure S, et al. Malaria transmission in Southern Madagascar: influence of the environment and hydro-agricultural works in sub-arid and humid regions: part 1. Entomological investigations. Acta Trop. 2004;89:193-203.

10. Ravoahangimalala RO, Randrianambinintsoa FJ, Tchuinkam T, Robert V. Malaria in the urban highland area of Antananarivo, Madagascar: bioecology of Anopheles arabiensis (in French). Bull Soc Pathol Exot. 2008;101:348-52.

11. WHO. Manual on practical entomology in malaria: vector bionomics and organization, part 2: methods and techniques. Geneva: World Health Organization; 1975. http://apps.who.int/iris/bitstream/10665/42481/2/ WHO_OFFSET_13_\%28part2\%29.pdf. Accessed 10 July 2015.

12. Grjebine A. Insectes Diptères Culicidae Anophelinae, Faune de Madagascar, vol. 22. Paris; 1966.

13. Scott JA, Brogdon WG, Collins FH. Identification of single specimens of the Anopheles gambiae complex by the polymerase chain reaction. Am J Trop Med Hyg. 1993:49:520-9.

14. Wirtz RA, Zavala F, Charoenvit Y, Campbell GH, Burkot TR, Schneider I, et al. Comparative testing of monoclonal antibodies against Plasmodium falciparum sporozoites for ELISA development. Bull World Health Organ. 1987;65:39-45.

15. Padley D, Moody AH, Chiodini PL, Saldanha J. Use of a rapid, single-round, multiplex PCR to detect malarial parasites and identify the species present. Ann Trop Med Parasitol. 2003;97:131-7.

16. Bashar K, Tuno N, Ahmed TU, Howlader AJ. False positivity of circumsporozoite protein (CSP) -ELISA in zoophilic anophelines in Bangladesh. Acta Trop. 2013;125:220-5.

17. Durnez L, Van Bortel W, Denis L, Roelants P, Al Veracx, Trung HD, et al. False positive circumsporozoite protein ELISA: a challenge for the estimation of the entomological inoculation rate of malaria and for vector incrimination. Malar J. 2011;10:195.

18. Beier JC, Perkins PV, Wirtz RA, Koros J, Diggs D, Gargan TP, et al. Bloodmeal identification by direct enzyme-linked immunosorbent assay (ELISA), tested on Anopheles (Diptera: Culicidae) in Kenya. J Med Entomol. 1988:25:9-16.

19. Tantely LM, Boyer S, Fontenille D. A review of mosquitoes associated with Rift Valley fever virus in Madagascar. Am J Trop Med Hyg. 2015;92:722-9. 
20. Jean Jose Nepomichene TN, Elissa N, Cardinale E, Boyer S. Species diversity, abundance, and host preferences of mosquitoes (Diptera: Culicidae) in two different ecotypes of Madagascar with recent RVFV transmission. J Med Entomol. 2015:52:962-9.

21. Fornadel CM, Norris LC, Franco V, Norris DE. Unexpected anthropophily in the potential secondary malaria vectors Anopheles coustani s.l. and Anopheles squamosus in Macha, Zambia. Vector Borne Zoonotic Dis. 2011;11:1173-9.

22. Bernard DJ, Leong Pock Tsy J-M, Rabarison P, Roux J, Coluzzi M, Costantini C. Zoophily of Anopheles arabiensis and An. gambiae in Madagascar demonstrated by odour-baited entry traps. Med Vet Entomol. 2001;15:50-7.

23. Ndiath MO, Mazenot C, Sokhna C, Trape JF. How the malaria vector Anopheles gambiae adapts to the use of insecticide-treated nets by African populations. PLoS One. 2014;9:e97700.
24. Govella NJ, Okumu FO, Killeen GF. Insecticide-treated nets can reduce malaria transmission by mosquitoes which feed outdoors. Am J Trop Med. 2010;82:415-9.

25. Killeen GF, Chitnis N. Potential causes and consequences of behavioural resilience and resistance in malaria vector populations: a mathematical modelling analysis. Malar J. 2014;13:97. doi:10.1186/1475-2875-1113-1197.

26. Ratovonjato J, Randrianarivelojosia M, Rakotondrainibe ME, Raharimanga V, Andrianaivolambo L, Le Goff G, et al. Entomological and parasitological impacts of indoor residual spraying with DDT, alphacypermethrin and deltamethrin in the western foothill area of Madagascar. Malar J. 2014;13:21. doi:10.1186/1475-2875-1113-1121.

\section{Submit your next manuscript to BioMed Central and we will help you at every step:}

- We accept pre-submission inquiries

- Our selector tool helps you to find the most relevant journal

- We provide round the clock customer support

- Convenient online submission

- Thorough peer review

- Inclusion in PubMed and all major indexing services

- Maximum visibility for your research

Submit your manuscript at www.biomedcentral.com/submit
(O) BioMed Central 